Received Date : 15-Sep-2014

Revised Date : 13-Dec-2014

Accepted Date : 03-Jan-2015

Article type : Original Article - Platelets

\title{
Anagrelide platelet-lowering effect is due to inhibition of both megakaryocyte maturation and proplatelet formation: insight into potential mechanisms
}

Espasandin YR, Glembotsky AC, Grodzielski M, Lev PR, Goette NP, Molinas FC, Marta RF, Heller PG

Departamento de Hematología Investigación. Instituto de Investigaciones Médicas Alfredo Lanari. Universidad de Buenos Aires. Consejo Nacional de Investigaciones Científicas y Técnicas (CONICET). Buenos Aires. Argentina

\section{Corresponding author:}

Paula G. Heller. Departamento de Hematología Investigación. Instituto de Investigaciones Médicas Alfredo Lanari. Universidad de Buenos Aires. CONICET. Combatientes de Malvinas 3150. Buenos Aires 1427. Argentina

Phone/Fax: +54114523 8947

Email address: paulaheller@ hotmail.com

\section{Short title}

Mechanisms of anagrelide platelet-lowering effect

This article has been accepted for publication and undergone full peer review but has not been through the copyediting, typesetting, pagination and proofreading process which may lead to differences between this version and the Version of Record. Please cite this article as an 'Accepted Article', doi: 10.1111/jth.12850

This article is protected by copyright. All rights reserved. 


\section{Summary}

\section{Background and Objectives}

Anagrelide represents a treatment option for essential thrombocythemia patients. It lowers platelet counts through inhibition of megakaryocyte maturation and polyploidization, although the basis for this effect remains unclear. Based on its rapid onset of action, we assessed whether, besides blocking megakaryopoiesis, anagrelide represses proplatelet formation (PPF) and aimed to clarify the underlying mechanisms.

\section{Methods and Results}

Exposure of cord blood-derived megakaryocytes to anagrelide during late stages of culture led to a dose- and time-dependent inhibition in PPF and reduced proplatelet complexity, which were independent of anagrelide-induced effect on megakaryocyte maturation. Whereas anagrelide was shown to phosphorylate cAMP-substrate VASP, two pharmacologic inhibitors of the CAMP pathway were completely unable to revert anagrelideinduced repression in megakaryopoiesis and PPF, suggesting these effects are unrelated to its ability to inhibit phosphodiesterase (PDE) 3 . The reduction in thrombopoiesis was not the result of downregulation of transcription factors which coordinate PPF, while the myosin pathway was identified as a candidate target, as anagrelide was shown to phosphorylate myosin light chain and the PPF phenotype was partially rescued after inhibition of myosin activity with blebbistatin.

\section{Conclusions}

The platelet-lowering effect of anagrelide results from impaired megakaryocyte maturation and reduced PPF, both of which are deregulated in essential thrombocythemia. These effects seem unrelated to PDE3 inhibition, which is responsible for anagrelide's cardiovascular side effects and antiplatelet activity. Further work on this field may lead to the potential development of drugs to treat thrombocytosis in myeloproliferative disorders with improved pharmacologic profile.

\section{Keywords}

Anagrelide, Cyclic AMP, Megakaryocyte, Myosin , Thrombopoiesis

This article is protected by copyright. All rights reserved. 


\section{Introduction}

Anagrelide is a platelet-lowering agent which represents a treatment option for patients with essential thrombocythemia [1,2]. It has a selective effect on megakaryocytes, while sparing the myeloid and erythroid lineages, rendering particularly useful for treatment of patients with isolated thrombocytosis. Anagrelide was originally developed as an antiplatelet agent [3], while the thrombocytopenic effect of this drug was discovered during preclinical trials [4]. Mazur et al demonstrated that anagrelide exerts its effects by influencing the postmitotic phase of megakaryocyte development, decreasing megakaryocyte ploidy and size [5], whereas it reduces megakaryocyte colony growth only at 10-fold higher in vitro concentrations, several-fold higher than those achieved in vivo, suggesting it has no relevant effect on megakaryocyte progenitors at therapeutic doses. Accordingly, although one study described reduced numbers of megakaryocytes by flow cytometric analysis of bone marrow samples from anagrelide-treated patients [6], this finding was not supported by bone marrow histological evaluation [7]. During normal megakaryocyte development, after reaching maturation, megakaryocytes form long, branched cytoplasmic extensions named proplatelets, which protrude into the bone marrow sinusoidal lumen where platelets are released from proplatelet tips, a process that is completed within a few hours [8]. Based on anagrelide's rapid onset of action, we hypothesized that besides blocking megakaryocyte polyploidization and maturation, anagrelide inhibits later stages of platelet production, characterized by proplatelet formation (PPF), which would result in faster changes in platelet counts.

Although anagrelide has been used in clinical practice since the late 1980's, the molecular mechanisms underlying its platelet-lowering activity remain still unclear. Results from initial studies using hematopoietic cell lines proposed that anagrelide interfered with signaling from the $\mathrm{Mpl}$ receptor [9], although subsequent data in primary human hematopoietic cells failed to support these observations [10]. More recently, megakaryocytes exposed to anagrelide at concentrations which inhibit megakaryocyte maturation were shown to express reduced levels of key megakaryocyte transcription factors, including GATA-1, FLI-1 and NF-E2 [10]. Whether anagrelide suppresses megakaryopoiesis by exerting a direct effect on megakaryocyte transcriptional axis or, alternatively, whether this finding reflects the presence of more immature megakaryocytes expressing lower levels of these transcriptional regulators is not clear from this study.

This article is protected by copyright. All rights reserved. 
Anagrelide inhibits cyclic adenosine monophosphate (cAMP) phosphodiesterase (PDE) 3 [11]. Stimulation of cAMP signaling by pharmacologic agents has been reported to block megakaryocyte differentiation and maturation [12]. Based on the fact that anagrelide is a PDE3 inhibitor, it is plausible to consider that its effects on the megakaryocyte are mediated through elevation of cAMP levels. Recently, megakaryocytic inhibition by cAMP was shown to be mediated by protein kinase $A(P K A)$-dependent downregulation of transcription factor E2A and its target CDKN1A (p21) and that, similarly, anagrelide represses this regulatory E2A/p21 loop, suggesting the potential involvement of cAMP in anagrelide's mechanism of action [13]. On the other hand, the fact that other commercially available PDE3 inhibitors have no effect on in vitro megakaryocyte maturation argues against the possible participation of this second messenger in anagrelide-induced platelet reduction [14]. In addition, certain differences exist between anagrelide's platelet antiaggregating activity, which is known to rely upon cAMP elevation, and its platelet lowering effect. First, inhibition of platelet function is achieved at higher anagrelide concentrations than those required for megakaryocyte inhibition [15]. Also, whereas its antiaggregating activity is seen in vitro and ex vivo in humans and several other species, the platelet-lowering effect is exerted only in humans, suggesting that different mechanisms mediate both actions [3,4]. However, as yet, the role of anagrelide's PDE3 inhibitory activity in its platelet-lowering effect has not been directly explored.

In this study, we show that besides blocking megakaryopoiesis, anagrelide exerts a direct inhibitory effect on thrombopoiesis and that both actions are, at least partly, independent of PDE3 inhibition. In addition, we explore other molecular mechanisms which may underlie the effects of this compound on platelet biogenesis and identify the myosin pathway as a potential target.

\section{Materials and Methods}

\section{Megakaryocyte culture and proplatelet formation}

After informed consent, CD34+ cells were purified by immunomagnetic separation (Miltenyi Biotech Ltd., Bisley, Surrey, UK) from cord blood, which was collected following normal deliveries, and from primary peripheral blood CD34+ cells obtained from a patient with essential thrombocythemia. Cells were cultured in StemSpan medium (Stem Cell Technologies, Vancouver, BC, Canada) supplemented with $10 \mathrm{ng} / \mathrm{mL}$ thrombopoietin (Miltenyi Biotec Ltd.) and $10 \eta \mathrm{g} / \mathrm{mL}$ interleukin 6 (Miltenyi Biotec Ltd.). To assess megakaryocyte maturation, cells were incubated with fluorescein isothiocyanate (FITC)-

This article is protected by copyright. All rights reserved. 
conjugated CD61 and CD42b-phycoerythrin (BD Biosciences, San José, CA, USA) followed by flow cytometry. To evaluate PPF, $10^{4}$ cells were seeded on 96-well plates at day 13 of culture, PPF was monitored daily by phase-contrast microscopy (Axiovert 25, Carl Zeiss $\mathrm{GmbH}$, Göttingen, Germany) and peak PPF was recorded, as described [16].

\section{Drug treatment}

Anagrelide hydrochloride (NewChem Technologies Limited, Durham, UK) was prepared in dimethylsulfoxide (DMSO) (Sigma-Aldrich). Control cultures were incubated with an equivalent amount of DMSO. Two different treatment schedules were used. In schedule A, which was used to assess the effect of anagrelide or dibutyryl (db)-CAMP (Sigma-Aldrich, St Louis, MO, USA) in megakaryopoiesis, cells were incubated with the selected compounds since day 1 of culture and exposed to the drugs all along the culture period until day 12, at which point analysis was carried out. In schedule B, which was applied to study PPF, cells were grown in the absence of drugs and these were added at day 13 of culture, including anagrelide, db-cAMP or prostaglandin (PG) E1 (Sigma-Aldrich). In selected experiments, cells were preincubated with the PKA inhibitor, PKI (14-22) amide (myristoylated) (Enzo Life Sciences, Plymouth Meeting, PA, USA), the competitive inhibitor Rp-cAMPS (SigmaAldrich), or the selective inhibitor of myosin II ATPase activity, blebbistatin (Sigma-Aldrich) during $30 \mathrm{~min}$. prior to anagrelide or db-cAMP addition, as indicated for each experiment.

\section{Immunofluorescence analysis of megakaryocytes and proplatelets}

Cells were cytocentrifuged, fixed with $3 \%$ paraformaldehyde, permeabilized with $0.2 \%$ Triton X-100, stained with CD61-FITC and Hoechst 33258 (Sigma-Aldrich) and analyzed under an epifluorescent microscope (Carl Zeiss $\mathrm{GmbH}$ ). Images were acquired using a digital camera (Canon Power Shot G6, Tokyo, Japan). Megakaryocytes were classified into maturation stages according to standard criteria [17] and megakaryocyte diameter was determined using the VideoTesT-Master Morphology image analysis software (St. Petersburg, USSR). To assess PPF on fibrinogen and proplatelet complexity, $1 \times 10^{5}$ megakaryocytes were treated with anagrelide or vehicle at day 13 of culture and seeded on fibrinogen-coated coverslips in 24-well plates, as described [16]. After 48 hours, cells were stained as detailed before. Then, PPF was assessed and the number of swellings and platelet-like structures (tips) on each proplatelet-bearing megakaryocyte were counted. Proplatelet length and maximum shaft thickness were analyzed with the same software used for image analysis. At least 40 megakaryocytes producing proplatelets were analyzed for each sample. To assess adhesion and spreading on collagen, day 13 megakaryocytes were treated or not with anagrelide and allowed to adhere to coverslips previously coated with $25 \mu \mathrm{g} / \mathrm{mL}$ type I

This article is protected by copyright. All rights reserved. 
collagen (kindly provided by Prof. Tura and Dr. Gruppi, University of Pavia, Italy), as described [18]. After 16 hours, non-adherent cells were removed and, after gentle washing, cells were fixed, stained with FITC-labeled phalloidin (Sigma-Aldrich) to assess percentage of cells showing spreading or with CD61 antibody to count the number of adherent megakaryocytes.

\section{Megakaryocyte gene expression analysis}

Cord blood-derived CD34+ cells were cultured as described before and allophycocyanin (APC)-conjugated CD41+ cells were purified on day 9 by fluorescence-activated cell sorting (FACSAria II, BD Biosciences), cell purity of the sorted population was 98\%. At day 13, megakaryocytes were incubated with $50 \eta \mathrm{M}$ anagrelide during 48 hours. Then, RNA was isolated from non-treated and treated cells using RNeasy Micro kit (Qiagen, Hilden, Germany). After reverse transcription, expression levels of target genes were measured in triplicate by real-time PCR relative to GAPDH using SYBR® Green (Life Technologies, NY, USA) in an iCycler (Bio Rad Life Science, CA, USA), primer sequences are listed in Table S1.

\section{Western blot analysis}

Cells were stimulated with anagrelide, db-cAMP or vehicle at concentrations detailed for each experiment and $1 \times 10^{6}$ cells were lysed with RIPA buffer $(50 \mathrm{mM}$ Tris- $\mathrm{HCl}, 150 \mathrm{mM}$ $\mathrm{NaCl}, 1 \% \mathrm{NP}-40,0.5 \%$ sodium deoxycholate, $0.1 \%$ SDS) and subjected to SDS-PAGE. In selected experiments, $2 \times 10^{6}$ cells were treated or not with anagrelide, allowed to adhere to $25 \mu \mathrm{g} / \mathrm{mL}$ type I collagen-coated 6 well-plates during 16 hours and lysed after removal of non-adherent cells. For immunoblotting, membranes were probed with rabbit polyclonal phospho (p)-vasodilator-stimulated phosphoprotein (VASP) (Ser157) antibody (Cell Signaling Technology, Danvers, MA) or mouse phospho-myosin light chain 2 (MLC2) (Ser19) monoclonal antibody (Cell Signaling Technology), followed by the corresponding horseradish peroxidase-conjugated secondary antibodies. Protein loading was assessed with anti- $\beta$-actin. A ratio between pVASP or pMLC2 and $\beta$-actin was calculated by densitometry.

\section{Statistical analysis}

Data are presented as mean \pm standard deviation (SD) or standard error of the mean (SEM), as indicated. Comparison between groups was performed using paired $t$-test or repeated measures ANOVA followed by Tukey's multiple comparison test. $P$ values $<0.05$ were considered significant.

This article is protected by copyright. All rights reserved. 


\section{Results}

\section{Anagrelide-induced inhibition in proplatelet formation}

First, we confirmed in our culture system that, as reported, exposure of cord blood-derived CD34+ cells to 500 $\mathrm{MM}$ anagrelide since the beginning and all along the culture period (day 1 to day 12) inhibits megakaryocyte maturation, as assessed by percentage of double positive $\mathrm{CD} 61+\mathrm{CD} 42 \mathrm{~b}+$ cells and stratification in maturation stages according to size and nuclear lobulation, without affecting megakaryocyte colony growth (data not shown). Then, to assess the effect of anagrelide on PPF, cord blood-derived megakaryocytes were grown for 12 days and, at day 13 of culture, cells were exposed to anagrelide. A dose-dependent inhibition in PPF was found (Fig.1A). However, although no cell toxicity was observed when cells were exposed to up to $1 \mu \mathrm{M}$ anagrelide during earlier stages of culture, exposure of day 13 mature megakaryocytes to $>250 \eta M$ led to increased cell death, as determined by Trypan blue exclusion (data not shown). Therefore, to evaluate PPF, subsequent experiments were performed using lower dosis. A significant reduction in proplatelet counts was found after incubation with $50 \eta \mathrm{M}$ anagrelide, $1.47 \pm 0.2$ vs. $4.80 \pm 0.5 \%, \mathrm{p}=0.0002$, paired $t$-test (Fig.1B,C). In addition to decreased PPF observed in cells in suspension, reduced PPF was reproduced when tested after megakaryocyte adhesion to fibrinogen, $1.39 \pm 0.10 \mathrm{vs}$. $3.27 \pm 0.19, \quad \mathrm{p}<0.0001$, paired $t$-test, $\mathrm{n}=5$. This treatment schedule did not affect megakaryocyte viability $(99.4 \pm 5.7 \%$ of control untreated cells), ploidy (Fig. S1A) and maturation, as assessed by \%CD61+CD42b+ cells $(70.45 \pm 6.2$ for $50 \eta \mathrm{M}$ anagrelide-treated cultures and $73.82 .11 \pm 6.7 \%$ for untreated cells, $P>0.05)$ and analysis of megakaryocyte maturation stages by immunofluorescence (Fig. S1B), indicating a direct effect of anagrelide in thrombopoiesis. To assess the time-course effect of anagrelide on PPF, megakaryocytes were incubated with 50ๆM anagrelide during increasing time periods. As shown (Fig 1D), the degree of PPF inhibition increased over time, reaching $52.33 \pm 9.9 \%, 27.16 \pm 1.5 \%, 19.3 \pm 4.2$ and $15.63 \pm 4.7 \%$ of control levels at $24,48,72$ and 96 -hour incubation period, respectively.

\section{Effect of anagrelide on proplatelet complexity from normal cord blood-derived and primary essential thrombocythemia megakaryocytes}

We then evaluated whether, besides reducing PP counts, anagrelide influences PP

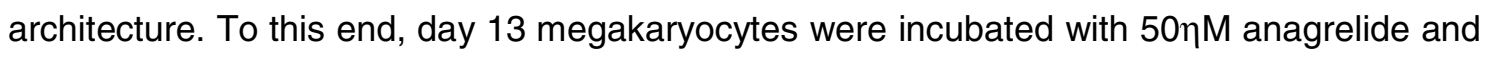
seeded on fibrinogen-coated matrices followed by immunofluorescence analysis. Anagrelide induced an overall reduction in proplatelet complexity, as shown by the decrease in the number of swellings for each proplatelet-bearing megakaryocyte, a trend towards reduced

This article is protected by copyright. All rights reserved. 
number of tips and decreased proplatelet length (Fig. 2A,B). In addition, proplatelet shafts were wider in anagrelide-treated megakaryocytes (Fig. 2A,B). To assess if the effect of anagrelide on PPF could be relevant in the clinical setting, primary CD34+ peripheral blood cells from an untreated patient with essential thrombocythemia were cultured in the same conditions as cord-blood cells. Percentage of double positive CD61+CD42b+ cells after 12 days of culture was $92.5 \%$. After exposure of mature megakaryocytes to 50ฤM anagrelide during 48hs, proplatelets from essential thrombocythemia megakaryocytes incubated with vehicle showed extensive ramification and numerous proplatelet tips, as previously reported [19], while a profound inhibition in PPF was found after incubation with 50ๆM anagrelide, reaching $7.96 \pm 0.6 \%$ of proplatelet counts obtained in untreated cells. In addition, the few proplatelets formed in the presence of anagrelide were poorly developed (Fig. 2C).

\section{Effect of anagrelide on megakaryocyte VASP phosphorylation}

To assess whether anagrelide's effects on the megakaryocyte are mediated by its ability to inhibit PDE3, we first studied whether this drug stimulates CAMP signaling in megakaryocytes by measuring the phosphorylation status of cAMP-substrate VASP on Ser157, which is the major PKA-dependent phosphorylation site. Results showed that treatment of cells with 500ๆM anagrelide during the whole culture period (day 1 to day 12), which was the schedule used to inhibit megakaryopoiesis, was capable of inducing VASP phosphorylation, while 48-hour incubation of mature day $13 \mathrm{MKs}$ with 50ๆM anagrelide, the approach used to inhibit thrombopoiesis (schedule B), did not modify pVASP levels (Fig.3A), which suggests that anagrelide-induced inhibition in PPF is unrelated to its PDE3 inhibitory activity. We then compared the effect of addition of increasing concentrations of cAMP analog dibutyryl (db)-cAMP since the onset and all along the culture period respect to those elicited by 500ๆM anagrelide in schedule A on VASP phosphorylation (shown in Fig 3B) and megakaryocyte maturation. The latter was assessed by measuring CD42b expression, which was $38,66,41$ and $32 \%$ of control levels for $500 \eta \mathrm{M}$ anagrelide and $10 \mu \mathrm{M}, 20 \mu \mathrm{M}, 35 \mu \mathrm{M} \mathrm{db}-$ CAMP, respectively. The finding that for similar degree of inhibition in megakaryocyte maturation, $20 \mu \mathrm{M}$ db-cAMP induced higher levels of pVASP as compared to anagrelide (Fig. 3B) suggests that anagrelide's effect on megakaryocyte maturation is, at least partly, unrelated to cAMP elevation.

This article is protected by copyright. All rights reserved. 


\section{Role of CAMP blockade in anagrelide-induced inhibition in megakaryothrombopoiesis}

We next assessed whether blockade of the cAMP pathway by two different pharmacologic inhibitors, the PKA inhibitor, PKI, and the competitive inhibitor Rp-cAMP, interfered with anagrelide's effect on megakaryopoiesis and thrombopoiesis. Neither 100ๆM PKI nor $500 \mu \mathrm{M}$ Rp-cAMP were able to revert anagrelide-induced inhibition in megakaryocyte maturation (Fig. 4A), while $100 \eta \mathrm{M}$ PKI was able to partially revert the effect of $20 \mu \mathrm{M} \mathrm{db}$ cAMP (data not shown), in accordance with recent data showing that cAMP exerts its inhibitory effect in the megakaryocyte lineage through a PKA-dependent mechanism [13]. Similar results were obtained when the addition of $500 \eta \mathrm{M}$ anagrelide was delayed until day 4 of culture and also when lower 250ๆM anagrelide concentrations or higher PKI doses, up to $1 \mu \mathrm{M}$, were used (data not shown). As for megakaryocyte maturation, neither 100ๆM PKI

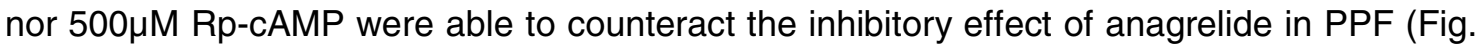
4B). Interestingly, we found that, in addition to its inhibitory effect in megakaryopoiesis, incubation of mature (day 13) megakaryocytes with $20 \mu \mathrm{M}$ db-cAMP reduced PPF, $1.88 \pm 0.6$ vs. $4.91 \pm 0.7, \mathrm{n}=7$ independent experiments, $\mathrm{P}<0.01$, paired $t$-test. Similar effect was obtained by treatment of cultures with $1 \mu \mathrm{M}$ cAMP-elevating agent PGE1, $1.29 \pm 0.18$ vs. $3.54 \pm 0.7, \mathrm{n}=4$ independent experiments, $\mathrm{p}<0.05$, paired $t$-test. Addition of $100 \eta \mathrm{M} \mathrm{PKI}$ prevented the inhibitory effect of $20 \mu \mathrm{M}$ db-cAMP on this process (Fig $4 \mathrm{C}$ ), showing that, as reported for megakaryopoiesis, cAMP inhibitory effect in PPF is also mediated by the PKA pathway. Altogether, these data indicate that, despite inducing mild activation of CAMPmediated pathways when used at 500ๆM, anagrelide's effects on the megakaryocyte seem to be, at least partly, independent of cAMP signaling. In contrast to its effects on the megakaryocyte, PKA blockade with PKI was able to partially revert anagrelide-mediated inhibition in platelet aggregation (Fig. S2), which is known to rely on its PDE3 inhibitory activity [15].

\section{Gene expression pattern of molecules involved in proplatelet formation in anagrelide- treated megakaryocytes}

To gain insight into the mechanisms underlying anagrelide-induced inhibition in PPF, we assessed whether short-term exposure of mature day 13 megakaryocytes with anagrelide at concentrations shown to inhibit PPF (e.g. 50ๆM) leads to dysregulation of transcription factors involved in thrombopoiesis. Levels of transcription factor NF-E2 and its targets, RAB27B and $\beta 1$-tubulin, as well as that of RUNX1 and the transcriptional complex megakaryoblastic leukemia 1 (MAL)/ serum response factor (SRF), and their common target,

This article is protected by copyright. All rights reserved. 
myosin light chain 2 (MLC2) were not reduced by anagrelide treatment (Fig. 5), indicating that anagrelide-induced inhibition in PPF is not due to decreased expression of these key molecular regulators of thrombopoiesis. In addition, no change in gene expression of the megakaryocytic regulator E2A, which is modulated by cAMP signaling, was found under these conditions (data not shown), whereas 500ๆM anagrelide has been reported to repress the E2A/p21 loop when added since the beginning of culture [13].

\section{Role of the myosin pathway in anagrelide-induced effects on the megakaryocyte}

Recent data highlight the key negative role of the Rho/Rho kinase/MLC2/myosin IIA cascade in proplatelet formation $[20,21]$. To evaluate the potential involvement of this pathway in anagrelide's effect on thrombopoiesis, we studied the phosphorylation status of MLC2 after treatment of megakaryocytes with 50ๆM anagrelide. As shown (Fig. 6A), anagrelide induced MLC2 phosphorylation on mature megakaryocytes, while, as expected [22], 20 $\mu \mathrm{M} d \mathrm{db}-\mathrm{cAMP}$ did not. Then, we evaluated whether the effect of anagrelide on thrombopoiesis could be reverted after blocking myosin II activity with blebbistatin. When mature day 13 megakaryocytes were incubated with increasing concentrations of blebbistatin prior to $50 \eta \mathrm{M}$ anagrelide addition, proplatelet counts rose up to control levels but did not reach levels achieved by blebbistatin alone (Fig. 6B), indicating that myosin inhibition can partially counteract the repressive effect of anagrelide in thrombopoiesis. Since MLC phosphorylation lies downstream of $\alpha 2 \beta 1$ collagen receptor engagement [23], we explored whether anagrelide modifies megakaryocyte behavior upon interaction with type I collagen. Incubation with 50ๆM anagrelide did not influence megakaryocyte adherence and spreading on type I collagen, $100.7 \pm 5.7$ and $93.9 \pm 15.3 \%$ of control, respectively, $n=3$, whereas adhesion to this extracellular matrix protein triggered similar levels of MLC phosphorylation in both control and anagrelide-treated cells (Fig. S3).

Considering that downregulation of non-muscle myosin IIB during normal megakaryocyte development is necessary for cells to undergo the mitosis-endomitosis switch favouring polyploidization [24], we assessed whether enhanced myosin activity could also be responsible for anagrelide-induced inhibition in megakaryopoiesis. To this end, blebbistatin was added at day 7 of culture followed by $500 \eta \mathrm{M}$ anagrelide during 72 hours, as longer incubation periods with blebbistatin were associated with cell toxicity. Megakaryocyte exposure to anagrelide alone during this short period induced a reduction in CD42b 
expression but had no significant effect on nuclear lobulation and size, preventing us from assessing the ability of blebbistatin to counteract the effect of anagrelide on these latter two parameters. Although blebbistatin was able to partially increase megakaryocyte lobulation and size in anagrelide-treated cells, as determined by assessment of megakaryocyte maturation stages and megakaryocyte diameter after immunofluorescence analysis (Fig. 7 $A, B, C$ ), it completely failed to reverse anagrelide-induced reduction in CD42b levels (Fig. 7D).

\section{Discussion}

Platelet biogenesis results from a complex process which involves differentiation of the hematopoietic stem cell to the megakaryocytic lineage, followed by megakaryocyte polyploidization and maturation leading to PPF and platelet release into the bloodstream. Fine tuning of platelet production occurs at multiple steps, including megakaryopoiesis and thrombopoiesis. Whereas the mechanisms governing megakaryopoiesis are well characterized, factors that guide PPF are beginning to be unraveled and comprise both intrinsic megakaryocytic signals and microenvironmental clues [25]. This study shows that besides its known effect in megakaryocyte maturation and polyploidization, anagrelide exerts a direct inhibitory effect on thrombopoiesis. This effect was evident at anagrelide in vitro concentrations which do not affect megakaryopoiesis (data not shown) and within those achieved in vivo, suggesting it may be relevant at regular therapeutic doses in the clinical setting. The inhibition in thrombopoiesis, which represents the final stages of platelet production and is accomplished within few hours, may contribute to the rapid onset of action of anagrelide. While megakaryocyte lineage expansion with increased numbers of mature megakaryocytes represent key features leading to thrombocytosis in essential thrombocythemia, more recently, enhanced PPF and increased proplatelet complexity have been shown to represent additional mechanisms leading to high platelet counts [19]. Therefore, anagrelide's platelet lowering effect occurs at two different levels, involving megakaryopoiesis and thrombopoiesis, both of which are deregulated in this myeloproliferative disorder. We show that in vitro anagrelide inhibits proplatelet formation also in primary megakaryocytes derived from a patient with essential thrombocythemia, further indicating that inhibition in thrombopoiesis contributes to anagrelide's therapeutic effect.

This article is protected by copyright. All rights reserved. 
Phosphodiesterase inhibition accounts for anagrelide-induced block in platelet aggregation and for its positive inotropic and vasodilatory properties, which lead to cardiovascular toxicity. Elevation of intracellular cAMP levels impairs megakaryocytic differentiation [12] and more recently, cyclic nucleotides have been shown to exert opposite effects on platelet release by mature murine megakaryocytes, with cAMP playing an inhibitory role and cGMP stimulating this event [26]. In this study, we confirm the repressive effect of cAMP on late stages of platelet production showing that, besides inhibiting megakaryopoiesis, cAMP interferes with PPF in a PKA-dependent manner, resembling anagrelide's dual action on the megakaryocyte lineage. Considering that anagrelide has been shown to raise cAMP levels in platelets [27], we assessed whether it is able to stimulate cAMP-dependent pathways in megakaryocytes. We show that, whereas anagrelide phosphorylates VASP when added at doses used to inhibit megakaryopoiesis (500ךM), no changes in pVASP levels are found when megakaryocytes are incubated with this compound at lower doses (50ฤM), which we show here to block thrombopoiesis. When compared with $20 \mu \mathrm{M}$ cAMP analog db-cAMP, for similar potency regarding their activity on megakaryopoiesis, anagrelide induced lower levels of pVASP, suggesting the involvement of CAMP-independent pathways in this effect. These findings together with the fact that blockade of the cAMP pathway is not able to revert anagrelide-induced inhibition in megakaryopoiesis and PPF argue against relevant participation of CAMP in this drug's platelet-lowering activity. Thus, the mechanisms underlying anagrelide's therapeutic effect, e.g. platelet reduction, seem to differ from those responsible for cardiovascular toxicity, which represents one of the most common adverse effects during anagrelide therapy, the latter being related and the former, unrelated, to PDE3 inhibition. Should it be possible to dissociate these actions, these findings could be translated into the potential development of novel platelet-lowering agents with improved pharmacologic profile. The recent development of rafigrelide, which is a chemical analog of anagrelide with reduced potency against PDE3, may help reduce side effects, while preserving its platelet-lowering activity [28].

Based on the finding that CAMP-independent pathways are involved in anagrelide-induced effects on the megakaryocytic lineage, we searched for other potential mechanisms which could underlie its platelet-lowering activity. First, we explored whether the block in thrombopoiesis could be explained by interference with transcription factors acting on late megakaryocyte stages. When mature megakaryocytes were treated with anagrelide using the schedule shown here to inhibit thrombopoiesis (e.g. 48-hour exposure to 501M anagrelide), levels of key transcription factors regulating proplatelet formation remained

This article is protected by copyright. All rights reserved. 
unchanged, including NF-E2, RUNX1 and MAL/ SRF, as well as that of their molecular targets involved in this event, such as RAB27B GTPase, $\beta 1$-tubulin and MLC2, indicating that the direct effect of anagrelide on thrombopoiesis is not a result of disturbance of the transcriptional network that coordinates this event.

Thrombocytopenia represents a major dose-limiting toxicity of certain drugs that block PPF by targeting the Rho/Rac/CDC42 cascade, including bortezomib and histone deacetylase inhibitors [29-31]. Modulation of this pathway leads to increased levels of phosphorylated MLC2, which enhances the motor acivity of non-muscle myosin IIA and inhibits PPF [20, 21]. In this study, we show that incubation of megakaryocytes with anagrelide results in MLC2 phosphorylation, which may represent a plausible explanation for the observed block in thrombopoiesis. The partial reversion of anagrelide-induced reduction in PPF achieved after inhibiting myosin II activity with blebbistation further supports this possibility. In contrast, the fact that myosin pathway blockade was not able to counteract the repressive effect of anagrelide on megakaryocyte maturation, as assessed by CD42b expression, indicates that additional mechanisms may be responsible for anagrelide's effects on megakaryopoiesis.

In conclusion, this work shows that anagrelide reduces platelet counts by targeting two sequential steps of platelet production, including megakaryocyte maturation and PPF from mature megakaryocytes. Whereas the block in thrombopoiesis may be ascribed to modulation of signals controlling myosin II activity, this pathway seems not to be involved on anagrelide's effect on megakaryocyte maturation, suggesting that more than a single molecular mechanism may be responsible for anagrelide platelet-lowering activity. Further work on the mechanisms underlying the effects of anagrelide on the megakaryocyte may contribute to our knowledge of the pathways regulating platelet biogenesis.

\section{Addendum}

Y. R. Espasandin designed and performed experiments, analyzed data, discussed results and prepared figures; A. C. Glembotsky, M. Grodzielzki, P. R. Lev and N. P. Goette performed experiments and/or analyzed data; F. C. Molinas provided vital reagents and discussed results; R. F. Marta designed and performed experiments, analyzed data and discussed results; P. G. Heller designed the study, performed and supervised experiments, analyzed data and wrote the paper. All authors contributed to manuscript editing and final approval.

This article is protected by copyright. All rights reserved. 
Authors state they have no conflicts of interests.

\section{Acknowledgements}

We are grateful to Shire Pharmaceuticals Limited, Hamshire, UK for provision of anagrelide hydrochloride. We wish to thank Sara Labat and nurses from the Departamento de Obstetricia, Hospital Materno Infantil "Dr. Carlos Gianantonio" for supply of cord blood samples and to Plácida Baz and Ariel Billordo, Laboratorio de Inmunogenética, Hospital de Clínicas “José de San Martín”, for helpful assistance with flow cytometry analysis and cell sorting. This work was supported by research grants from the Consejo Nacional de Investigaciones Científicas y Técnicas (CONICET) and from the Agencia Nacional de Promoción Científica y Tecnológica (ANPCyT).

\section{References}

1. Silverstein MN, Petitt RM, Solberg LA Jr, Fleming JS, Knight RC, Schacter LP. Anagrelide: a new drug for treating thrombocytosis. N Engl J Med 1988; 318: 1292-4.

2. Angrelide Study Group. Anagrelide, a therapy for thrombocythemic states: experience in 577 patients. Anagrelide Study Group. Am J Med 1992; 92: 69-76.

3. Fleming JS, Buyniski JP. A potent new inhibitor of platelet aggregation and experimental thrombosis, anagrelide (BL-4162A). Thromb Res. 1979; 15: 373- 88.

4. Abe Andes W, Noveck RJ, Fleming JS. Inhibition of platelet production induced by an antiplatelet drug, anagrelide, in normal volunteers. Thromb Haemost 1984; 52: 325-8.

5. Mazur EM, Rosmarin AG, SohI PA, Newton JL, Narendran A. Analysis of the Mechanism of Anagrelide-Induced Thrombocytopenia in Humans. Blood 1992; 79: 1931-37.

6. Tomer A. Effects of anagrelide on in vivo megakaryocyte proliferation and maturation in essential thrombocythemia. Blood 2002; 99: 1602-9.

7. Thiele J, Kvasnicka HM, Fuchs N, Brunnbauer K, Volkwein N, Schmitt-Graeff A. Anagrelide-induced bone marrow changes during therapy of chronic myeloproliferative disorders with thrombocytosis. an immunohistochemical and morphometric study of sequential trephine biopsies. Haematologica 2003; 88: 1130-8.

8. Thon JN, Italiano JE. Platelet formation. Semin Hematol 2010; 47: 220-6.

9. McCarty JM, Melone PD, Simanis JP, Kanamori D, Dessypris EN, Warshamana-Greene GS. A preliminary investigation into the action of anagrelide: thrombopoietin-c-Mpl receptor interactions. Exp Hematol 2006; 34:87-96.

10. Ahluwalia M, Donovan H, Singh N, Butcher L, Erusalimsky JD. Anagrelide represses GATA-1 and FOG-1 expression without interfering with thrombopoietinreceptor signal transduction. J Thromb Haemost 2010; 8: 2252-61.

11. Gillespie E. Anagrelide: a potent and selective inhibitor of platelet cyclic AMP phosphodiesterase enzyme activity. Biochem Pharmacol 1988; 37: 2866-8.

12. Freson K, Peeters K, De Vos R, Wittevrongel C, Thys C, Hoylaerts MF, Vermylen J, Van Geet C. PACA and its receptor VPAC1 regulate megakaryocyte maturation: therapeutic implications. Blood 2008; 111:1885-93.

13. Rubinstein JD, Elagib KE, Goldfarb AN. Cyclic AMP signaling inhibits megakaryocytic differentiation by targeting transcription factor 3 (E2A) cyclin-dependent kinase inhibitor $1 \mathrm{~A}$ (CDKN1A) transcriptional axis. J Biol Chem 2012; 287: 19207-15.

This article is protected by copyright. All rights reserved. 
14. Wang G, Franklin R, Hong Y, Erusalimsky JD. Comparison of the biological activities of anagrelide and its major metabolites in haematopoietic cell cultures. Br J Pharmacol 2005; 146: 324-32.

15. Schacter LP, Doyle G. Investigator's Brochure: Anagrelide. Pharmaceutical Research Institute, Bristol-Myers Company, july 15, 1991.

16. Lev PR, Grodzielski M, Goette NP, Glembotsky AC, Espasandin YR, Pierdominici MS, Contrufo G, Montero VS, Ferrari L, Molinas FC, Heller PG, Marta RF. Impaired proplatelet formation in immune thrombocytopenia: a novel mechanism contributing to decreased platelet count. Br J Haematol 2014; 165: 854-64.

17. Williams N, Levine RF. The origin, development and regulation of megakaryocytes. $\mathrm{Br} \mathrm{J}$ Haematol 1982; 52: 173-180.

18. Balduini A, Pallotta I, Malara A, Lova P, Pecci A, Viarengo G, Balduini CL, Torti M. Adhesive receptors, extracellular proteins and myosin IIA orchestrate proplatelet formation by human megakaryocytes. J Thromb Haemost 2008; 6: 1900-7.

19. Balduini A, Badalucco S, Pugliano MT, Baev D, De Silvestri A, Cattaneo M, Rosti V, Barosi G. In vitro megakaryocyte differentiation and proplatelet formation in Ph-negative classical myeloproliferative neoplasms: distinct patterns in the different clinical phenotypes. PLoS One 2011; 6: e21015.

20. Chen Z, Naveiras O, Balduini A, Mammoto A, Conti MA, Adelstein RS, Ingber D, Daley GQ, Shivdasani RA. The May-Hegglin anomaly gene MYH9 is a negative regulator of platelet biogenesis modulated by the Rho-ROCK pathway. Blood 2007; 110: 171-9.

21. Chang Y, Auradé F, Larbret F, Zhang Y, Le Couedic JP, Momeux L, Larghero J, Bertoglio J, Louache F, Cramer E, Vainchenker W, Debili N. Proplatelet formation is regulated by the Rho/ROCK pathway. Blood 2007; 109: 4229-36.

22. Aburima A, Wraith KS, Raslan Z, Law R, Magwenzi S, Naseem KM. CAMP signaling regulates platelet myosin light chain (MLC) phosphorylation and shape change through targeting the RhoA-Rho kinase-MLC phosphatase signaling pathway. Blood. 2013; 122: 3533-45.

23. Sabri S, Jandrot-Perrus M, Bertoglio J, Farndale RW, Mas VM, Debili N, Vainchenker W. Differential regulation of actin stress fiber assembly and proplatelet formation by alpha2beta1 integrin and GPVI in human megakaryocytes. Blood 2004; 104: 3117-25

24. Lordier L, Bluteau D, Jalil A, Legrand C, Pan J, Rameau P, Jouni D, Bluteau O, Mercher T, Leon C, Gachet C, Debili N, Vainchenker W, Raslova H, Chang Y. RUNX1-induced silencing of non-muscle myosin heavy chain IIB contributes to megakaryocyte polyploidization. Nat Commun 2012; 3: 717.

25. Machlus KR, Italiano JE Jr. The incredible journey: From megakaryocyte development to platelet formation. J Cell Biol 2013; 201: 785-96.

26. Begonja AJ, Gambaryan S, Schulze H, Patel-Hett S, Italiano JE Jr, Hartwig JH, Walter $U$. Differential roles of cAMP and cGMP in megakaryocyte maturation and platelet biogenesis. Exp Hematol 2013; 41: 91-101.

27. Seiler S, Arnold AJ, Grove RI, Fifer CA, Keely SL Jr, Stanton HC. Effects of anagrelide on platelet cAMP levels, cAMP-dependent protein kinase and thrombin-induced $\mathrm{Ca}++$ fluxes. J Pharmacol Exp Ther 1987; 243: 767-74.

28. Balasubramaniam K, Viswanathan G, Dragone J, Grose-Hodge R, Martin P, Troy S, Preston P, Zaman AG. Antithrombotic properties of rafigrelide: a phase 1, open-label, nonrandomised, single-sequence, crossover study. Thromb Haemost 2014; 112; 1: 205-15.

29. Bishton MJ, Harrison SJ, Martin BP, McLaughlin N, James C, Josefsson EC, Henley KJ, Kile BT, Prince HM, Johnstone RW. Deciphering the molecular and biologic processes that mediate histone deacetylase inhibitor-induced thrombocytopenia. Blood. 2011; 117: 365868.

This article is protected by copyright. All rights reserved. 
30. Murai K, Kowata S, Shimoyama T, Yashima-Abo A, Fujishima Y, Ito S, Ishida Y. Bortezomib induces thrombocytopenia by the inhibition of proplatelet formation of megakaryocytes. Eur J Haematol 2014; 93: 290-6.

31. Shi DS, Smith MC, Campbell RA, Zimmerman PW, Franks ZB, Kraemer BF, Machlus KR, Ling J, Kamba P, Schwertz H, Rowley JW, Miles RR, Liu ZJ, Sola-Visner M, Italiano JE $\mathrm{Jr}$, Christensen $\mathrm{H}$, Kahr WH, Li DY, Weyrich AS. Proteasome function is required for platelet production. J Clin Invest 2014; 124: 3757-66.

\section{Figure legends}

Figure 1. Anagrelide inhibits proplatelet formation. A) Dose-dependent effect of anagrelide (ANA) on PPF. At day 13 of culture, megakaryocytes were harvested, replated in fresh medium and treated with increasing concentrations of anagrelide. The percentage of proplatelet-forming megakaryocytes grown in suspension cultures was monitored by phasecontrast microscopy. A dose-dependent reduction in proplatelet formation was found. Results represent mean $\pm S E M, n=2$ independent experiments. B) Inhibition in PPF induced by $50 \eta \mathrm{M}$ anagrelide. A significant decrease in thrombopoiesis compared to control cells is shown, $\mathrm{n}=6$ independent experiments, ${ }^{* \star *} P<0.001$, paired $t$-test $\mathrm{C}$ ) Representative images of control (left panel) and 50ๆM anagrelide-treated (right panel) cultures, showing fewer proplatelet-bearing megakaryocytes in the latter. Arrows indicate proplatelets. Insets show a magnified view of proplatelets in control and anagrelide-treated cutures. D) Time course effect of $50 \eta \mathrm{M}$ anagrelide on proplatelet formation. Megakaryocytes were treated with $50 \eta \mathrm{M}$ anagrelide during increasing periods of time, showing that the degree of inhibition in PPF increases over time. Data represent mean \pm SEM, $\mathrm{n}=3 .{ }^{\star *} P<0.01,{ }^{\star \star} P<0.001$, repeated measures ANOVA.

Figure 2. A) Decrease in proplatelet complexity in megakaryocytes treated with anagrelide.

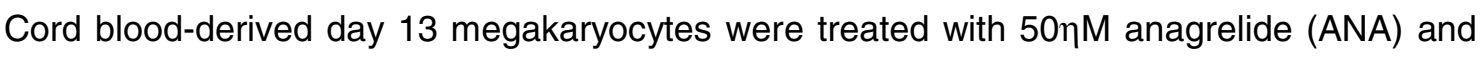
plated on fibrinogen matrices. After 48-hour incubation, megakaryocytes were fixed, stained with FITC-conjugated CD61 antibody and Hoescht and proplatelets were analyzed by fluorescence microscopy. Panel A shows control cord blood-derived proplatelet-bearing megakaryocytes and panel $B$ illustrates proplatelets in cells exposed to anagrelide, showing decreased overall complexity. B) The effect of anagrelide on proplatelet architecture was analyzed using an image analysis software. Results show a trend towards reduced number of tips, a decrease in the number of swellings for each proplatelet-bearing megakaryocyte, a reduction in proplatelet length and increased maximum shaft width in megakaryocytes exposed to anagrelide. Data are mean \pm SEM of 4 independent experiments, ${ }^{\star *} P<0.01$,

This article is protected by copyright. All rights reserved. 
paired $t$-test. C) Effect of anagrelide on proplatelet formation from primary megakaryocyte culture derived from peripheral blood CD34+ cells from a patient with essential thrombocythemia. Megakaryocytes were grown in suspension and exposed to 501M anagrelide after reaching maturation and proplatelet formation was monitored by phasecontrast microscopy. Representative image showing proplatelets with extensive ramification in untreated culture is depicted in the left panel, whereas only rudimentary proplatelets are seen after incubation with anagrelide (right panel).

Figure 3. A) Effect of anagrelide on VASP phosphorylation. Cells were exposed to anagrelide (ANA) as detailed below, then cell lysates were immunoblotted using antiphospho ( $p$ )-VASP $\left(\operatorname{Ser}^{157}\right)$ antibody and membranes were reprobed with anti- $\beta$-actin antibody. Treatment of megakaryocytes (MKs) with 500ๆM anagrelide since day 1 to day 12 of culture (schedule A, as detailed in Materials and Methods) (left lanes), induced VASP phosphorylation, while no change in p-VASP was evident after addition of 50ฤM anagrelide to mature day 13 megakaryocytes during a 48-hour period in schedule B (right lanes). Incubation of platelets with $100 \mu \mathrm{M}$ dibutyryl (db)-cAMP is shown as a positive control for VASP phosphorylation. Relative optical density (OD) between pVASP and $\beta$-actin is depicted in the lower panel. B) Effect of increasing concentrations of db-cAMP compared to $500 \eta \mathrm{M}$ anagrelide on megakaryocyte p-VASP levels. Densitometric analysis of reactive bands illustrating $p-V A S P / \beta$-actin ratio is shown on the bar graph.

Figure 4. (A) Effect of protein kinase $A$ inhibitor, $P K I$, and competitive inhibitor Rp-cAMP on anagrelide-induced inhibition in megakaryocyte maturation. Preincubation with $100 \eta \mathrm{M} \mathrm{PKI}$ or $500 \mu \mathrm{M}$ Rp-cAMP failed to revert the inhibitory effect of $500 \eta \mathrm{M}$ anagrelide (ANA) added since day 1 to day 12 (treatment schedule $A$, as detailed in Material and Methods) on the percentage of CD41+CD42b+ cells, $\mathrm{n}=3$ independent experiments, ${ }^{* *} P<0.01$, ${ }^{* \star *} P<0.001$ vs. untreated control, †† and \#\# $P<0.01$ vs. PKI and Rp-cAMP, respectively, repeated measures ANOVA. (B) Effect of PKI and Rp-cAMP on anagrelide-induced inhibition in thrombopoiesis. As shown, incubation of cells with both pharmacologic inhibitors prior to cell exposure to $50 \eta \mathrm{M}$ anagrelide from day 13 to day 15 under schedule $B$ was not able to counteract the block in proplatelet formation, $\mathrm{n}=3$ independent experiments, ${ }^{* *} P<0.01$ vs. untreated control, †† $P<0.01$ vs. PKI and \#P<0.05 vs. Rp-cAMP, respectively, repeated measures ANOVA. (C) Reversal of $20 \mu \mathrm{M}$ dibutyryl (db)-cAMP-induced inhibition in proplatelet formation by pretreatment with $100 \eta \mathrm{M}$ PKI PKI, $\mathrm{n}=3$ independent experiments, ** $P<0.01$, ns: non-significant vs. untreated control, repeated measures ANOVA.

This article is protected by copyright. All rights reserved. 
Figure 5. Gene expression levels of molecules involved in proplatelet formation in mature megakaryocytes incubated with anagrelide. Megakaryocytes were differentiated from cord blood CD34+ cells, then CD41+ cells were purified by fluorescence activated cell sorting at day 9 and exposed to 50ๆM anagrelide (ANA) at day 13 during 48 hours, after which mRNA levels of selected genes were measured by qPCR and normalized to GAPDH. Error bars represent mean $\pm \mathrm{SD}$ of triplicate.

Figure 6. A) Myosin light chain phosphorylation status in anagrelide-treated megakaryocytes. Mature day 13 megakaryocytes were exposed to 50ๆM anagrelide (ANA) during 48hs, lysed and immunoblotted with phospho-myosin light chain (MLC) 2 (Ser19) antibody. Membranes were reprobed with $\beta$-actin. pMLC2 phosphorylation is shown in cells treated with anagrelide, while exposure to $20 \mu \mathrm{M}$ dibutyryl (db)-cAMP failed to induce MLC2 phosphorylation. B) Effect of blebbistatin on anagrelide-induced inhibition in thrombopoiesis. Mature day 13 megakaryocytes were incubated with increasing concentrations of blebbistatin during $30 \mathrm{~min}$., then exposed to $50 \eta \mathrm{M}$ anagrelide and proplatelet formation was monitored by phase-contrast microcopy. Blebbistatin induced a dose-dependent increase in proplatelet counts in control cultures and in cells incubated with anagrelide, and partially reverted anagrelide-induced inhibition in proplatelet formation, $n=3$ independent experiments, ${ }^{*} P<0.05{ }^{* *} P<0.01{ }^{* * *} P<0.001$ vs control, $+\dagger \dagger P<0.001$ vs the corresponding concentration of blebbistatin for each condition (e.g. $25 \mu \mathrm{M}, 50 \mu \mathrm{M}$ and $100 \mu \mathrm{M}$ blebbistatin, respectively), repeated measures ANOVA.

Figure 7. Effect of blebbistatin on anagrelide-induced inhibition in megakaryopoiesis. Day 7 megakaryocytes were incubated with $20 \mu \mathrm{M}$ blebbistatin during $30 \mathrm{~min}$. followed by treatment with 500ๆM anagrelide (ANA). On day 10, megakaryocyte nuclear lobulation and size were assessed by immunofluorescence analysis and CD42b mean fluorescence intensity (MFI) was measured by flow cytometry. A) Blebbistatin (Bleb) increased megakaryocyte lobulation, as assessed by the percentage of cells classified as stage II and III, in control cells and had a partial effect on cells treated with anagrelide, $\mathrm{n}=5$ independent experiments, ${ }^{*} P<0.01$ vs untreated, $\uparrow \dagger P<0.01$ vs anagrelide, repeated measures ANOVA. B) Representative image of immunofluorescence analysis using CD61-conjugated FITC and Hoescht of untreated cells or cells treated from day 7 to day 10 with $500 \eta \mathrm{M}$ anagrelide, $20 \mu \mathrm{M}$ blebbistatin or $20 \mu \mathrm{M}$ blebbistatin followed by $500 \eta \mathrm{M}$ anagrelide, as indicated. C) Blebbistatin increased megakaryocyte size in control cells and, partially, in anagrelide-treated cells, $n=5$ independent experiments, ${ }^{*} P<0.01$ vs untreated, $\dagger P<0.01$ vs anagrelide, repeated 
measures ANOVA. D) Blebbistatin had a mild effect on CD42b expression in control cells but not in cells treated with anagrelide, failing to revert anagrelide-induced reduction in CD42b levels. $\mathrm{n}=4$ independent experiments, ${ }^{* *} P<0.01$, ${ }^{* * *} P<0.001$ vs. untreated control, ††† $P<0.001$ vs blebbistatin, repeated measures ANOVA.

\section{Supporting information}

Supplementary Figure 1. A. Ploidy analysis of megakaryocytes treated with anagrelide. Cells were grown in the absence of anagrelide, then day 13 megakaryocytes were incubated with $50 \eta \mathrm{M}$ anagrelide during 48 hours and ploidy was measured in the CD61+ population by flow cytometry after permeabilization with $0.1 \%$ Tween, and incubation with $100 \mu \mathrm{g} / \mathrm{mL}$ propidium iodide and $100 \mu \mathrm{g} / \mathrm{mL}$ RNAse. Mean ploidy was calculated by taking into account number of cells in each ploidy class relative to total number of cells and was $2.4 \mathrm{~N}$ for control cells and $2.6 \mathrm{~N}$ for anagrelide-treated cells. B. Analysis of megakaryocyte maturation stages after immunofluorescence staining showed no significant difference between treated and control cells, $n=4$ independent experiments.

Supplementary Figure 2. Partial reversal of anagrelide-induced inhibition in platelet aggregation by preincubation with PKI. Platelet-rich-plasma from a healthy individual was prepared by centrifugation at $200 \mathrm{~g}$ during $10 \mathrm{~min}$. and adjusted to $300 \times 10^{9} / \mathrm{L}$. Platelets were incubated with $10 \mu \mathrm{M} \mathrm{PKI}$ or vehicle during $10 \mathrm{~min}$. at $37^{\circ} \mathrm{C}$, then exposed to $1 \mu \mathrm{M}$ anagrelide or vehicle at $37^{\circ} \mathrm{C}$ during $10 \mathrm{~min}$. and stimulated with $2 \mu \mathrm{M}$ ADP (Biopool, Bray, Ireland). Aggregation was evaluated using a lumi-aggregometer (Chrono Log Corp, Havertown, PA, USA) and results were expressed as percentage of maximal light transmission. Aggregation traces of platelets incubated with vehicle, anagrelide alone and PKI followed by anagrelide and then stimulated with ADP are shown.

Supplementary Figure 3. Myosin light chain phoshorylation after adhesion to type I collagen. Day 13 megakaryocytes were treated or not with $50 \eta \mathrm{M}$ anagrelide and allowed to adhere to plates coated with $25 \mu \mathrm{g} / \mathrm{mL}$ type I collagen during 16 hours. After removal of nonadherent cells, adherent cells were lysed and pMLC2 levels were assessed by western blot, showing similar phosphorylation levels in both control and anagrelide-treated megakaryocytes adhering to collagen.

This article is protected by copyright. All rights reserved. 
Supplementary Table 1. List of primer sequences used por qPCR analysis.

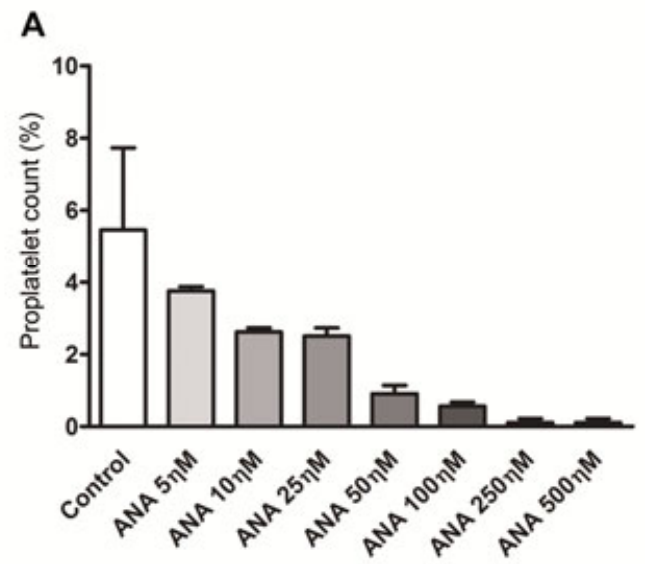

B

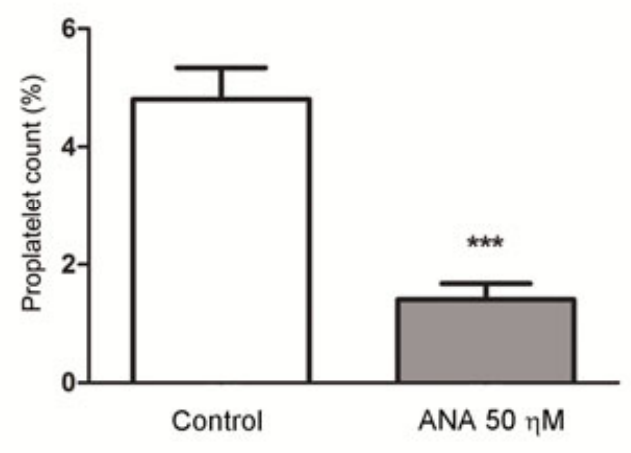

C
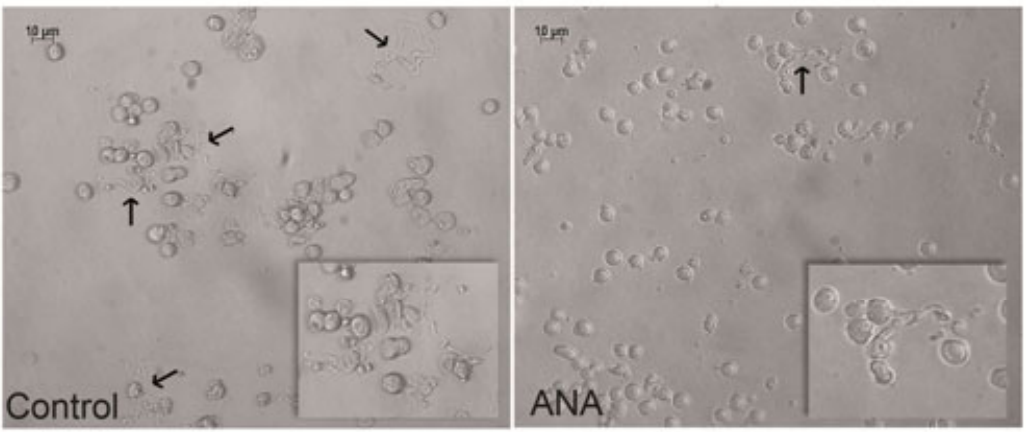

D

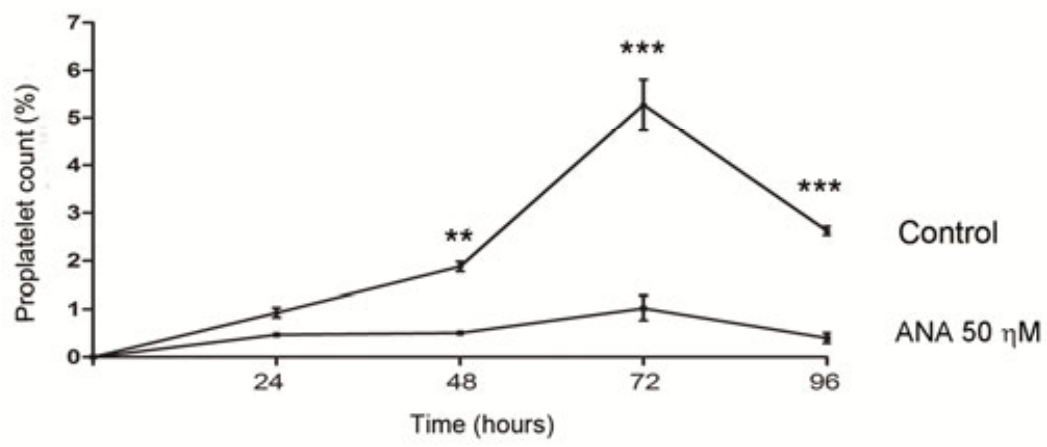


A Cord blood-derived MKs
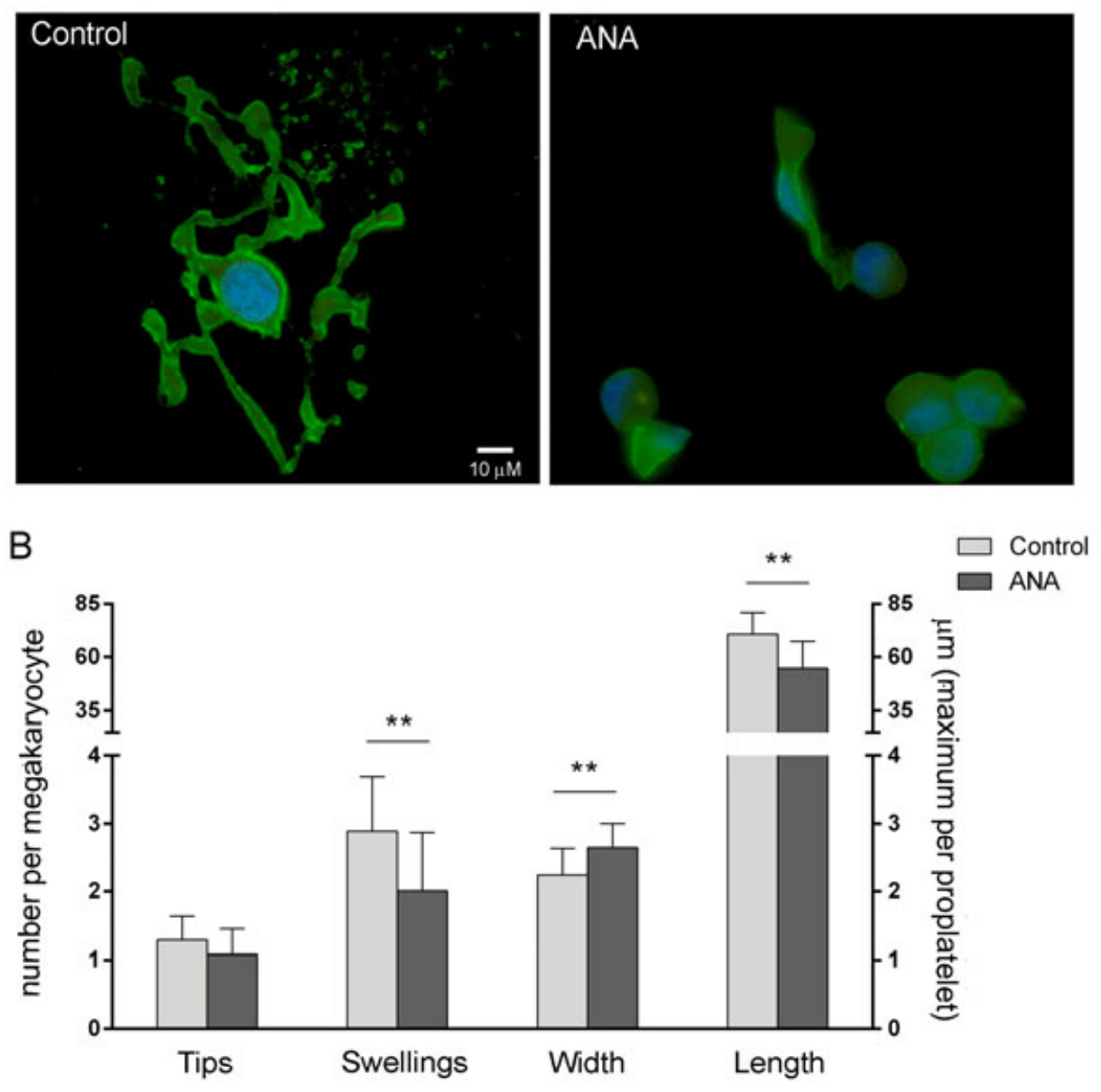

C Primary essential thrombocythemia MKs
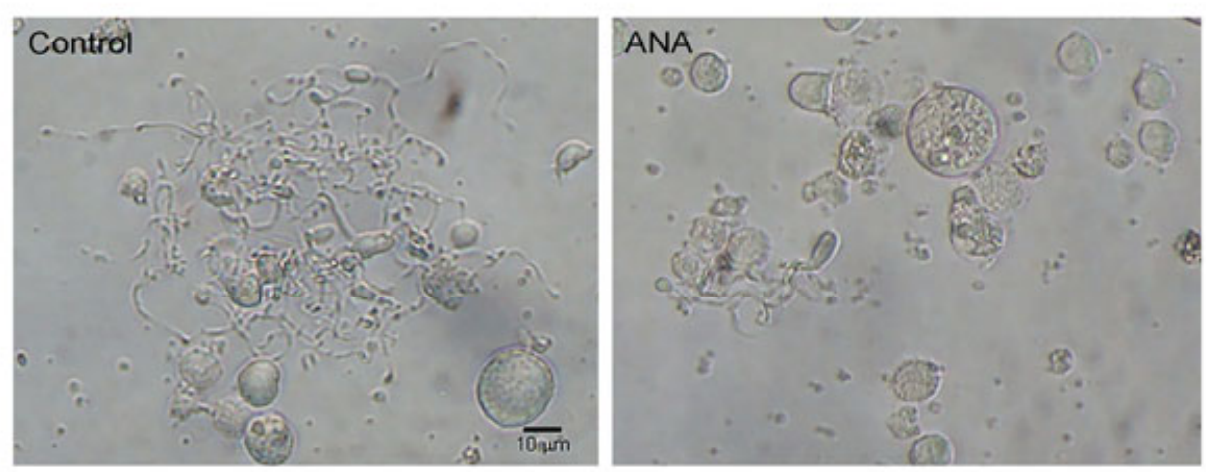
A
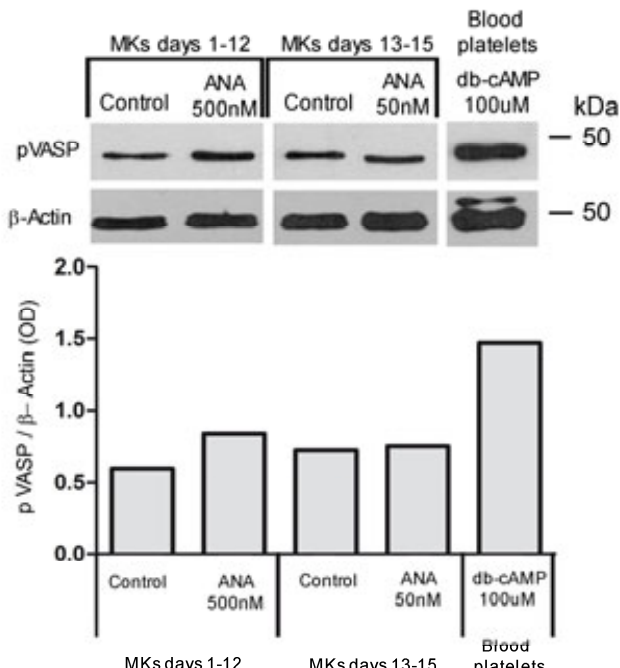

B
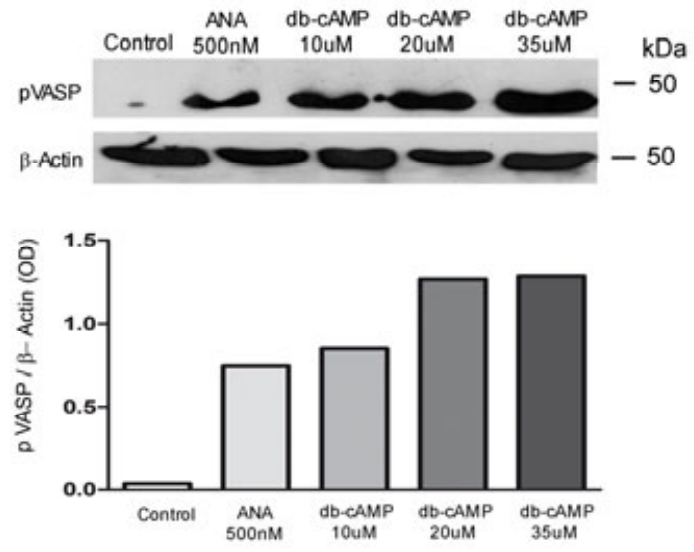


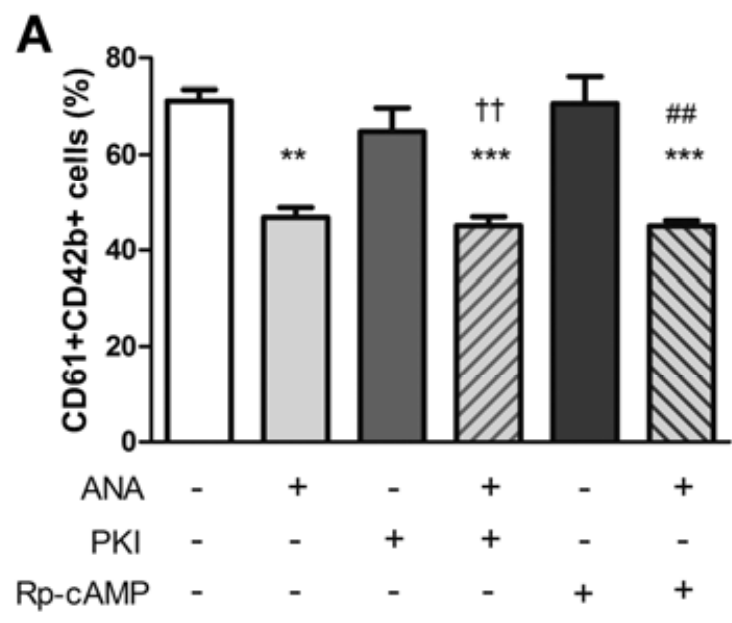

\section{B}

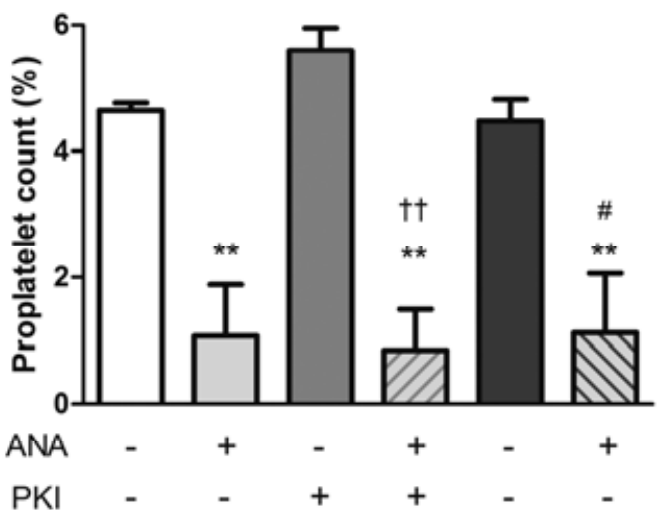

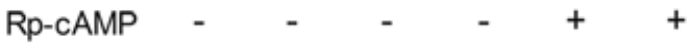

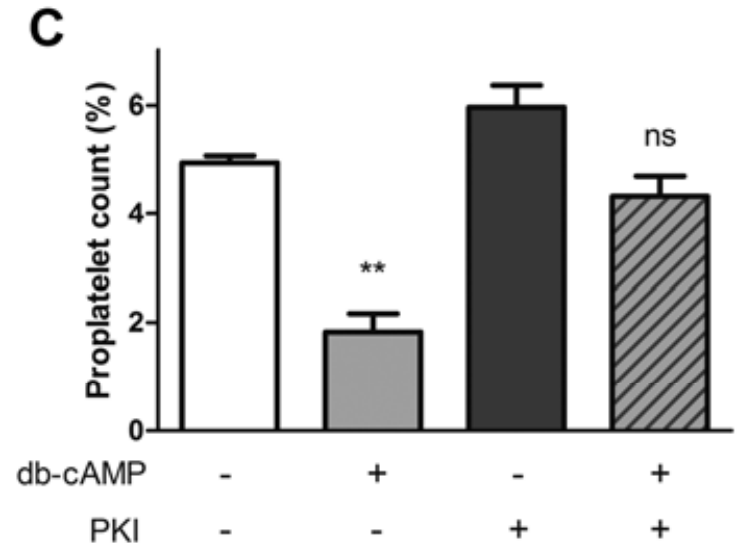




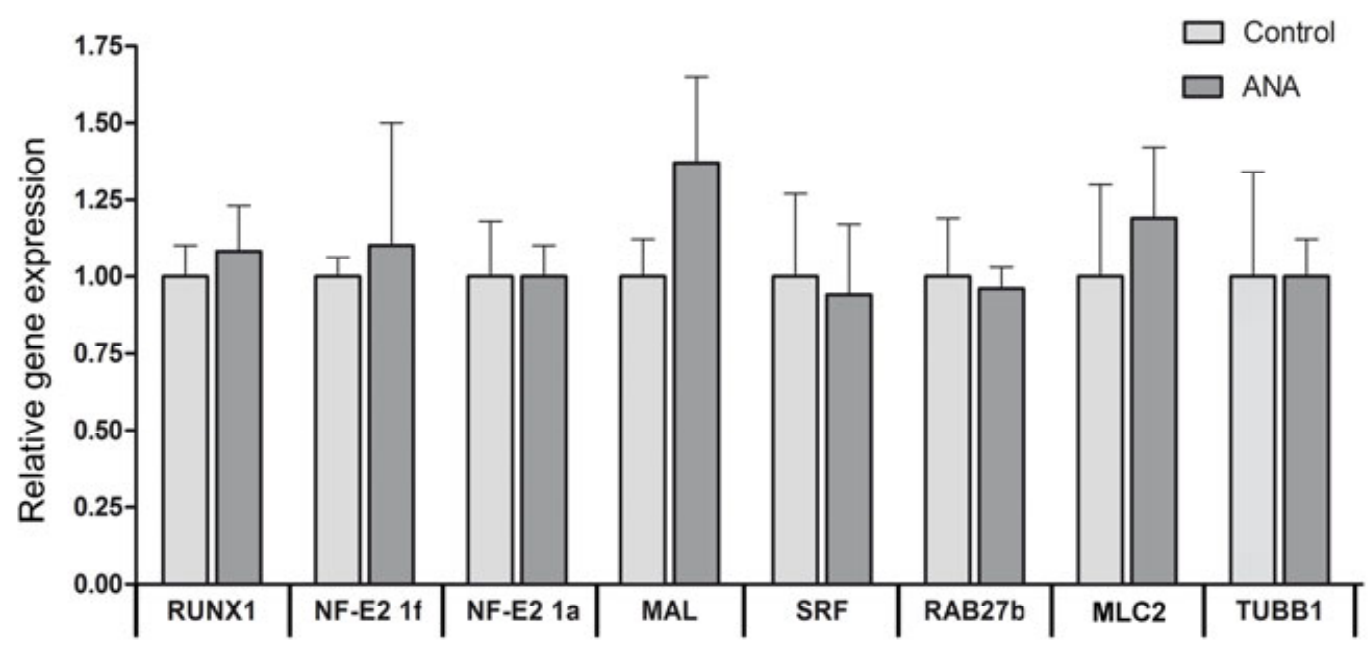

A
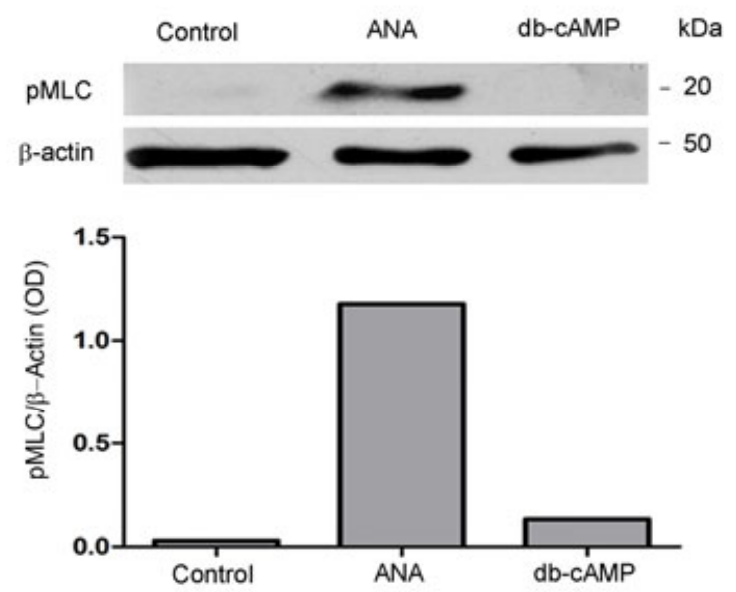

B

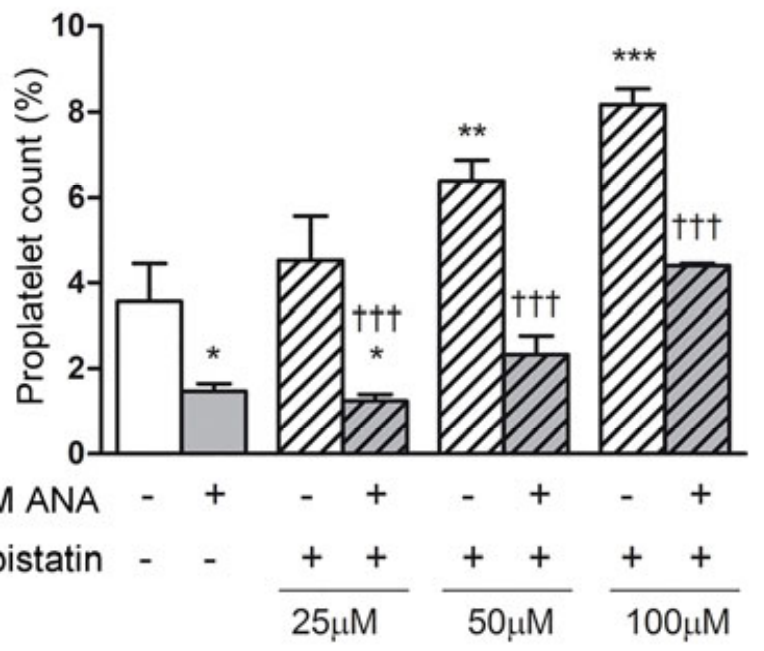

This article is protected by copyright. All rights reserved. 
A

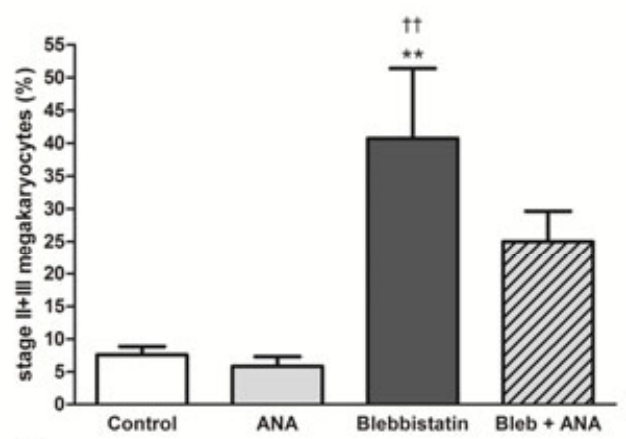

C

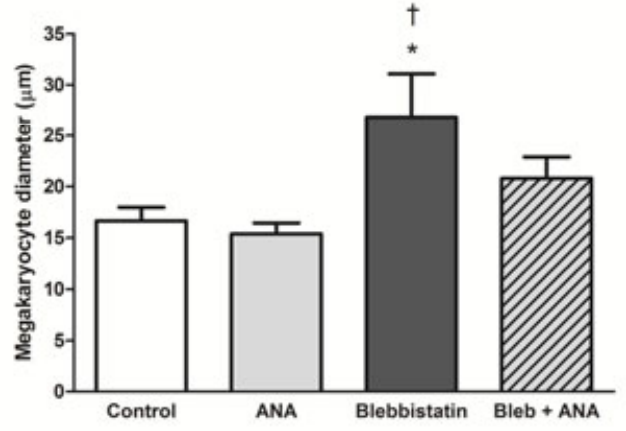

B

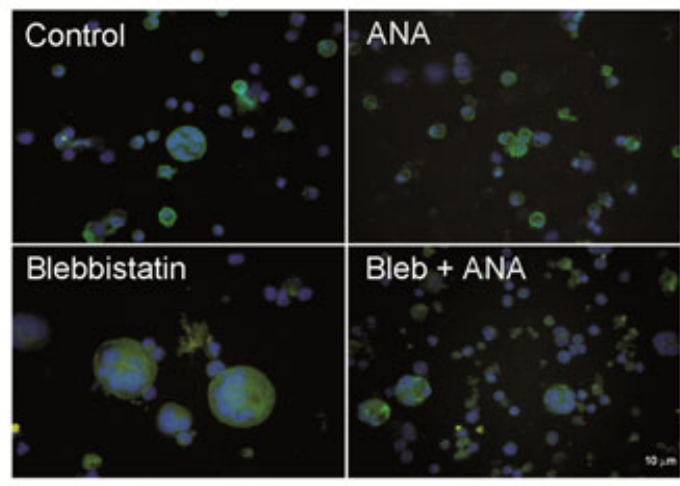

D

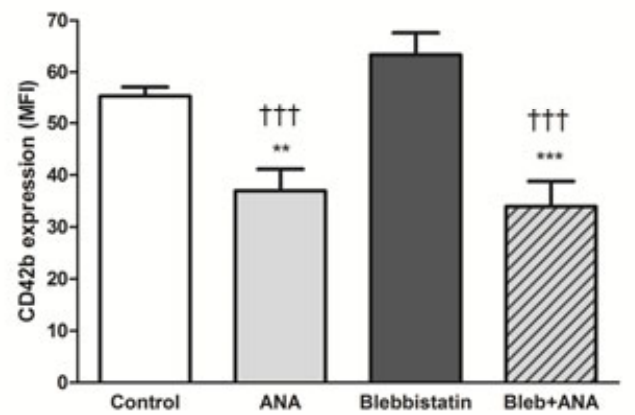

